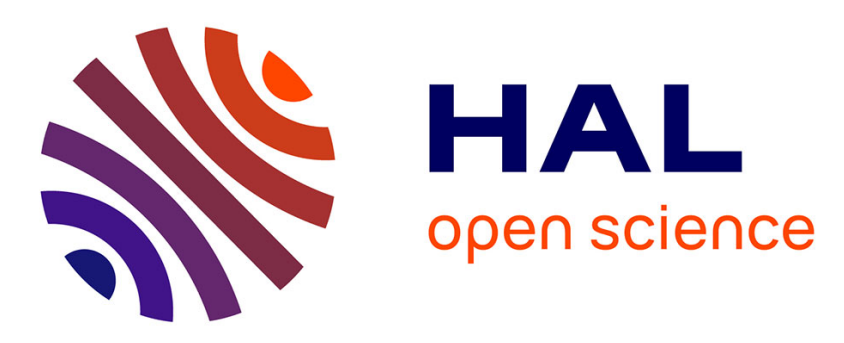

\title{
Distribution of insecticide resistance and molecular mechanisms involved in the West Nile vector Culex pipiens in Morocco
}

Soukaina Arich, Najlaa Assaid, Hassan Taki, Mylène Weill, Pierrick Labbé, M'Hammed Sarih

\section{To cite this version:}

Soukaina Arich, Najlaa Assaid, Hassan Taki, Mylène Weill, Pierrick Labbé, et al.. Distribution of insecticide resistance and molecular mechanisms involved in the West Nile vector Culex pipiens in Morocco. Pest Management Science, In press, 10.1002/ps.6127 . hal-02961654

\section{HAL Id: hal-02961654 \\ https://hal.umontpellier.fr/hal-02961654}

Submitted on 8 Oct 2020

HAL is a multi-disciplinary open access archive for the deposit and dissemination of scientific research documents, whether they are published or not. The documents may come from teaching and research institutions in France or abroad, or from public or private research centers.
L'archive ouverte pluridisciplinaire HAL, est destinée au dépôt et à la diffusion de documents scientifiques de niveau recherche, publiés ou non, émanant des établissements d'enseignement et de recherche français ou étrangers, des laboratoires publics ou privés. 


\section{Distribution of insecticide resistance and molecular mechanisms involved in the West Nile vector Culex pipiens in Morocco}

Running head: Cx.pipiens insecticide resistance in Morocco

Soukaina Arich ${ }^{1,3}$, Najlaa Assaid ${ }^{3}$, Hassan Taki ${ }^{1}$, Mylène Weill ${ }^{2}$, Pierrick Labbé2£ and M'hammed Sarih ${ }^{3 * £}$.

1- Laboratory of Biology and Health, URAC 34, Hassan II University-Casablanca, Faculty of Sciences Ben M’Sik. Casablanca.

2- Institut des Sciences de l'Evolution de Montpellier (UMR 5554, CNRS-UM-IRD-EPHE), Université de Montpellier, Place Eugène Bataillon, 34095 Montpellier, CEDEX 5, France.

3- Laboratoire des Maladies Vectorielles (LMV), Institut Pasteur du Maroc, 1 Place Louis Pasteur, 20100 Casablanca, Morocco.

${ }^{£}$ These authors contributed equally to this work

* corresponding author

Dr. M’hammed Sarih

Laboratoire des Maladies Vectorielles (LMV)

Institut Pasteur du Maroc

1 Place Louis Pasteur.

20360 Casablanca

e-mail : mhammed.sarih@pasteur.ma

Author's e-mail adresses: SA: arichsoukaina@gmail.com, NA: najlaa.essaid@gmail.com, HT:

hassantaki308@gmail.com, MW: mylene.weill@umontpellier.fr, PL : pierrick.labbe@umontpellier.fr, MS : mhammed.sarih@pasteur.ma

This article has been accepted for publication and undergone full peer review but has not been through the copyediting, typesetting, pagination and proofreading process which may lead to differences between this version and the Version of Record. Please cite this article as doi: $10.1002 /$ ps.6127 


\begin{abstract}
BACKGROUND: Mosquitoes of the Culex pipiens complex are the vectors of several arboviruses, and are thus subjected to insecticide control worldwide. However, overuse of insecticides selects for resistance. While assessing the resistance status of the vectors is required for effective and sustainable disease control, resistance has so far only been sparsely studied in Morocco. In this study, we establish a first countrywide assessment of the levels of resistance to various insecticides and potential responsible mechanisms involved.

Cx. pipiens larvae have been collected from natural populations of five regions of Morocco, and their taxonomic status has been determined (molecular forms). The level of their susceptibility to insecticides was assessed by single-diagnostic-dose bioassays. Molecular identification of known resistance alleles was investigated to determine the frequency of target-site mutations.

RESULTS: This study confirms that Moroccan populations are an interbreeding mix of pipiens and molestus forms, with large gene flow for the resistance alleles. We also found that $C x$. pipiens mosquitoes are resistant to all insecticide families, all over Morocco: resistance is high for insecticides used in mosquito control, but also present for other pesticides. Resistance alleles are similarly more frequent for mosquito control insecticides. However, their distribution is heterogeneous in the five regions, with significant genetic differentiation between populations, revealing the crucial role of local insecticide treatment practices.

CONCLUSION: This study provides reference countrywide data that highlight the need for further research to refine the distribution of resistance in Morocco and to understand the role of agriculture/urban residuals in its spread.
\end{abstract}

Key words: target-site resistance, metabolic resistance, arbovirus vectors, molestus, pipiens. 


\section{INTRODUCTION}

Emerging and re-emerging vector-borne diseases are becoming increasingly important in animal and public health. According to the World Health Organization, they are responsible for more than $17 \%$ of infectious diseases and cause more than one million deaths each year ${ }^{1}$. Most vector-borne diseases affecting human health are zoonoses that require a cycle of amplification involving zoophilic mosquitoes and vertebrate hosts other than humans ${ }^{2}$. This is the case for many arboviruses (arthropod-borne viruses): the mosquito Culex pipiens is for example the vector of several arboviruses like West Nile (WNV), Rift Valley Fever and St Louis encephalitis viruses ${ }^{3}$. The reservoirs of WNV are birds, with epidemics occurring as a result of virus transmission to equidae and humans. Epizootics/epidemics have been regularly observed in Europe (1684 confirmed cases in December 2018, including 181 deaths, according to the European Centre for Disease Prevention and Control ${ }^{4}$, and in Morocco, several outbreaks of WNV have been reported in 1996, 2003, $2010^{5-8}$.

Mosquitoes of the $C x$. pipiens complex proliferate in sites heavily polluted by organic matter produced by human activities (sewage treatment plants, sewers and wastewater collectors, etc.). In the southern Mediterranean regions in particular, the socio-economic changes of recent decades have favored the fast development of urban centers, sometimes however with inadequate sanitation facilities. Rural exodus to already-densely populated cities has created favorable conditions for $C x$. pipiens proliferation. Several forms of the $C x$. pipiens complex coexist in Morocco and hybridize ${ }^{9}$ : the pipiens form is capable of diapause, anautogenic and eurygame, whereas the molestus form is autogenous and stenogamous ${ }^{10-14}$, and does not diapause ${ }^{15}$. $C x$. pipiens mosquitoes are now the predominant urban mosquito species, leading to an increased risk of arboviral epizootics and epidemics.

In the absence of effective treatment and vaccines against these arboviruses, mosquito population control is the main strategy for limiting pathogen transmission. In this context, the 
use of insecticides plays a key role in the prevention and control of vector-borne diseases. In Morocco during the 1950s, treatment of larvae began with the use of DDT, an organochlorate insecticide. This was used until 1978 when an organophosphate insecticide (OP), temephos, was introduced ${ }^{16}$. However, mosquitoes control is threatened by insecticide resistance. Insecticide resistance is widespread worldwide, and multiple mechanisms have been selected due to the increasing pressure of insecticides used in public health but also in agriculture ${ }^{17-20}$. Two main groups of resistance mechanisms are recognized: metabolic resistance and resistance through modification of the insecticide target. In $C x$. pipiens (as in most mosquito species), metabolic resistance results from strong increases in the expression of detoxifying enzymes that inactivate or sequester insecticidal molecules. These enzymes belong mostly to three major families: the glutathion S tranferases, cytochrome P450 oxidases, and the esterases. The latter, causing resistance to OP and carbamate (CX) insecticides, is the most studied in this species ${ }^{21-23}$. The main target modifications result in reduced susceptibility to the insecticide. In $C x$. pipiens, they are due to mutations in the genes encoding i) the voltagegated sodium channel (vgsc locus; L1014F kdr mutations), the target of the pyrethroids insecticides (PYR) target ${ }^{24}$, ii) the acetylcholinesterase (AChE1; ace-1 locus, G119S and F290V mutations), the target of OP and CX insecticides ${ }^{25,26}$, and iii) the gamma aminobutyric acid receptor (GABA; Rdl locus, A302S mutation), the target of dieldrin (OC) ${ }^{27}$. Moreover, certain mechanisms allow resistance to several insecticide molecules, sometimes of different families: this cross-resistance severely limits the choice of alternative insecticides ${ }^{28-30}$. Finally, it has recently been shown that resistance can increase $C x$.pipiens' vectorial competence for WNV, which may therefore lead to an increased risk of epidemics ${ }^{31}$. In order to anticipate and establish informed management of insecticide resistance as part of plans for the prevention and/or management of vector-borne disease outbreaks, knowing the mechanisms present in a given region and their frequency is required ${ }^{32}$. In contrast with Tunisia and Algeria, where various resistance alleles have been detected in Cx. pipiens mosquitoes, often at high frequencies ${ }^{33,34}$, very little work has been done in Morocco on the mechanisms of insecticide resistance (this is also true for other vectors, as only Anopheles labranchiae has been studied so $\operatorname{far}^{16}$ ). Nevertheless, we have recently reported that wild 
populations of $C x$. pipiens in Mohammedia have developed resistance to OC, OP, CX and PYR insecticides ${ }^{35}$.

The objective of the present study was thus to assess and map the resistance levels and the different resistance mechanisms present in natural populations of the $C x$. pipiens species complex in Morocco. Only OPs and PYRs are used for mosquito control in Morocco, but mosquitoes can be exposed to other insecticide families, used in agriculture for example ${ }^{20}$. Therefore, resistance to the four families of insecticides usually used in vector control (PYR, OP, CX and OC) was evaluated for both molestus and pipiens forms in five regions of Morocco: Tangier (north), Larache (northwest), Mohammedia (center west), Marrakech (center) and Agadir (south west). Resistance mechanisms were characterized and the resistance alleles frequency analyzed in the different populations and taxons. In all of them, we found resistance to all insecticides, but with varying frequencies. This work constitutes a first reference to assess the dynamics of insecticide resistance in Morocco, with the ultimate goal of establishing a temporal and predictive projection of the risk of transmission, to assist the health authorities in their vector control strategy.

\section{METHODS}

\subsection{Mosquito samples}

Cx. pipiens was collected as larvae using the dipping sampling method during summer 2018 in 5 regions of Morocco (one sample per region), in various types of breeding sites and in different climatic regions representative of the country (Fig. 1): 1) sewer water in humid climate (Tanger, 3546 44.3" N5 $50^{\prime} 50.1^{\prime \prime W}$ ), 2) wet meadows in sub-humid climate (Larache, 35¹0'55.7" N607'56.8"W), 3) sewer water in humid climate (Mohammedia, 3340'25.33"N7²6'42.5"W), 4) irrigation canals in arid climate (Marrakech, $\left.31^{\circ} 38^{\prime} 12.7^{\prime \prime N} 8^{\circ} 10^{\prime} 07.0^{\prime \prime W}\right)$, 5) sewage water mixing in Souss river in sub-arid climate (Agadir, 30²1'39.8"N9²9'22.6"W). The strain Slab was used as the susceptible reference strain ${ }^{36}$. Part of the larvae were analyzed directly using bioassay, the others were brought back to the lab and reared until adulthood for molecular analyses. 


\subsection{Bioassays}

Mortality following insecticide exposure was determined by single-diagnostic-dose bioassays on fourth instar larvae collected in the field and brought to the lab. The insecticides, propoxur (CX), temephos (OP), permethrin (PYR), dieldrin (OC) and chlorpyrifos (OP), were purchased from Dr Ehrenstorfer GmbH, Germany. Each compound was dissolved in ethanol, with a final concentration of ethanol of $1 \%$ for all doses and all insecticides. For each insecticide, 2 cups were prepared for the Slab as susceptible strain, and 4 cups for the tested population. 2 cups of tested populations were prepared without insecticide as control. In each cup, 20-30 larvae were added to $100 \mathrm{ml}$ of water. The lowest dose of insecticide killing all the Slab larvae (100\% mortality) was then added to each cup (the doses have been found through bioassays on Slab strain larvae with various does of insecticide) : $2 \mathrm{mg}^{-1} \mathrm{l}^{-1}$ for propoxur, $0.0003 \mathrm{mg} . \mathrm{l}^{-1}$ for temephos, $0.005 \mathrm{mg} . \mathrm{l}^{-1}$ for permethrin, $0.01 \mathrm{~g} . \mathrm{l}^{-1}$ for dieldrin and $0.003 \mathrm{mg} . \mathrm{l}^{-}$

${ }^{1}$ for chlorpyrifos. We then recorded the mortality after 24 hours.

\subsection{Molecular analyses}

For each population, $\approx 60$ mosquito larvae were analyzed by PCR tests to characterize their taxonomy and genotypes for 5 resistance mutations. The DNA fragments were separated on 1.5\% agarose gel electrophoreses and visualized by ethidium bromide staining under ultraviolet light.

\subsubsection{Molecular identification of $C x$. pipiens forms}

DNA was extracted individually using the DNAzol method according to the manufacturer's protocol. Multiplex PCR tests were used to identify the $C x$. pipiens complex, as described by Bahnck \& Fonseca $^{37}$. The CQ11 locus was used to distinguish the two forms of $C x$. pipiens (pipiens and molestus) and their hybrids, using the primers pipCQ11R and molCQ11R, with the following PCR conditions: 30 seconds at $94^{\circ} \mathrm{C}, 30$ seconds at $54^{\circ} \mathrm{C}$ and 40 seconds at $72^{\circ} \mathrm{C}$. The different sizes of the amplified DNA fragment, $200 \mathrm{bp}$ for pipiens and $250 \mathrm{bp}$ for molestus, allows distinguishing the two forms and their hybrids in a single PCR reaction.

\subsubsection{Detection of the L1014F mutation in the vgsc locus}


The PASA diagnostic test of Martinez Torrez et al ${ }^{38}$ was used to genotype the samples for the vgsc L1014F mutation, except that the two separate PCRs were performed in parallel on each mosquito, PCR1 for the susceptible S alleles (L1014), using the primers Cgd1, Cgd2 and Cgd3, and PCR2 for the resistance R allele (F1014), Cgd1, Cgd2 and Cgd4. PCR conditions were $1 \mathrm{~min}$ at $94^{\circ} \mathrm{C}, 2 \mathrm{~min}$ at $48^{\circ} \mathrm{C}$ and $2 \mathrm{~min}$ at $72^{\circ} \mathrm{C}$ for 40 cycles. PCR 1 amplifies a common fragment for all individuals, and a specific fragment if the mosquito carries a $\mathrm{S}$ allele. PCR2 amplifies a common fragment for all individuals, and a specific fragment if the mosquito carries a R allele. The two PCR together thus allows distinguishing homozygotes and heterozygotes.

\subsubsection{Detection of the G119S and F290V mutations in the ace-1 locus}

The PCR-RFLP diagnostic test of Weill et al ${ }^{39}$ was used to genotype the individuals for the ace-1 G119S mutation. Briefly, a 374 bp fragment was amplified from exon 3 using the primers CpEx3dir and CpEx3rev, with the following PCR conditions: 30 seconds at $95^{\circ} \mathrm{C}, 30$ seconds at $52^{\circ} \mathrm{C}$ and 1 minute at $72^{\circ} \mathrm{C}$, for 30 cycles. The PCR product was then digested by the restriction enzyme AluI, according to the manufacturer's instructions (Jena Bioscience, Jena, Germany). The $\mathrm{S}$ allele is not digested, whereas the $\mathrm{R}$ allele is cleaved into two fragments, which allows distinguishing homozygotes and heterozygotes.

The PASA diagnostic test of Alout et al ${ }^{26}$ was used to genotype the individuals for the ace-1 F290V mutation. Briefly, 543 bp control fragment was amplified using the primers CxEx5dir and CxKrev2, 148 bp fragment specific of phenylalanine was amplified using the primers Valdir/CxKrev2 and 435 bp fragment specific of valine was amplified using the primers, with the following PCR conditions : were 30 seconds at $94^{\circ} \mathrm{C}, 30$ seconds at $51^{\circ} \mathrm{C}$ and 40 second at $72^{\circ} \mathrm{C}$, for 30 cycles.

\subsubsection{Detection of A302S mutation in the Rdl locus}

The PCR-RFLP diagnostic test of Tantely et al ${ }^{27}$ was used to genotype the individuals for the Rdl A302S mutation. Briefly, a 232 bp fragment was amplified by PCR with mqGABAdir and mqGABArev, with the following PCR conditions: 30 seconds at $94^{\circ} \mathrm{C}$ for, 30 seconds at $52^{\circ} \mathrm{C}$ and 1 minute at $72^{\circ} \mathrm{C}$, for 30 cycles. The PCR product was then digested by the 
restriction enzyme BstAPI according to the manufacturer's instructions (Jena Bioscience, Jena, Germany) instructions. The $\mathrm{R}$ allele is not digested, whereas the $\mathrm{S}$ allele is cleaved into two fragments, which allows distinguishing homozygotes and heterozygotes.

\subsubsection{Detection of the Ester ${ }^{2}$ allele at the Ester locus}

The PCR-RFLP diagnostic test Berticat et al ${ }^{40}$ was used to genotype the individuals for Ester $^{2}$ (A2-B2). The EsterA allele fragments were amplified using the primers EstAdir and EstArev, whereas the EsterB allele fragments were amplified using the primers EstBdir and EstBrev, with following PCR conditions: 30 seconds at $95^{\circ} \mathrm{C}$ for, 30 seconds at $52^{\circ} \mathrm{C}$ and 1 minute at $72^{\circ} \mathrm{C}$, for 30 cycles for the Ester $\mathrm{A}$ and 30 seconds at $95^{\circ} \mathrm{C}$ for, 30 seconds at $52^{\circ} \mathrm{C}$ and 1 minute at $72^{\circ} \mathrm{C}$, for 30 cycles for the EsterB. The PCR product was then digested by the restriction enzyme HaeIII for EsterA and HinfI for EsterB according to the manufacturer's instructions (Jena Bioscience, Jena, Germany) instructions.

\subsection{Statistical analyses}

All computations were performed using the R free software (v.3.3.1, http://www.r-project.org, The R core Team).

Frequency data for the different mutations were analyzed, using the genepop R package: the Hardy-Weinberg equilibrium was verified for each sample, and the genotypic differentiation of the different samples from Morocco was evaluated using $F_{s t}{ }^{41,42}$.

For each resistance mutation independently, the number of individuals for each genotype ( $N G$, i.e. RR, RS and SS numbers) were also compared between the different forms of $C x$. pipiens (FORM) and in the different localities (LOC). The significance of the observed differences was assessed with the following multinomial log-linear model (MLLM), using the nnet $\mathrm{R}$ package: $N G=$ FORM + LOC + FORM: LOC, where FORM is a 3-level factor (pipiens, molestus or hybrid), LOC is a 5-level factor (one for each locality), and FoRM:LOC represents the interaction between the two factors. The models were simplified as follows (Crawley 2007): significance of the different terms was tested starting from the higher-order terms using likelihood ratio tests (LRT). Non-significant terms $(p>0.05)$ were removed. Factor levels that were not significantly different (LRT) were grouped. 


\section{RESULTS AND DISCUSSION}

\subsection{Moroccan Culex pipiens are resistant to most common insecticides}

To assess the diversity and prevalence of insecticide resistances in $C x$. pipiens from Morocco, we first used single-diagnostic-dose bioassays on field-collected fourth instar larvae from five regions (Fig. 1). The proportion of individuals surviving the minimal dose killing all Slab larvae (i.e. the reference susceptible strain) is shown in Figure 2 for various insecticides from different families. Resistance to temephos (OP), chlorpyrifos (OP) and permethrin (PYR), was found very prevalent in all five populations, with mortality rates ranging from $4.34 \%$ to 26.5\% for both OP, and from $4.3 \%$ to $19.33 \%$ for permethrin. By contrast, mortality was generally high with propoxur (CX) (range $=63 \%$ in Tanger to $93 \%$ in Larache), and moderate to high for dieldrin (OC) (range $=50 \%$ in Larache to $96 \%$ in Marrakech). Resistance to all main families of insecticides is thus present in mosquito natural populations from Morocco. It confirms previous studies and suggests that many types of insecticides are used in Morocco. Only OPs and PYRs are allowed for public health, which could explain the high level of resistance observed for these families. However, the presence of resistance to CXs and OCs also suggest that mosquitoes are exposed to other sources of insecticides, for example from agriculture or urban residuals, as found for several mosquitoes ${ }^{43-46}$.

\subsection{Moroccan $C x$. pipiens populations are a mix of two molecular forms with many} hybrids

Two distinct forms of the $C x$. pipiens complex, pipiens and molestus, are morphologically identical but have significant behavioral and physiological differences. In the northern regions of Europe, Russia and the USA, these forms occupy different habitats, respectively surface and underground, whereas in Morocco a study found that both forms can co-occur in breeding sites ${ }^{9}$. To analyze the taxonomic diversity of $C x$.pipiens in the different sampled localities, we genotyped 60 mosquitoes per population using the CQ11 PCR diagnostic test ${ }^{37}$. We found that most individuals appear as hybrids (from 31.7\% in Tanger to 61.7\% in Agadir), and that the pipiens form (18.3 to $63.3 \%$ ) was more common than the molestus form (1.7 to $16.7 \%$ ) in these populations (Tab. 1). 
Table 1: Diversity and distribution of the C. pipiens forms in Morocco. The number of individuals from each form or hybrid and their frequencies in the sampled populations are indicated.

\begin{tabular}{cccccc}
\hline & Tanger & Larache & Mohammedia & Marrakech & Agadir \\
\hline Forms & N (\%) & N (\%) & N (\%) & N (\%) & N (\%) \\
\hline pipiens & $38(63.33)$ & $25(41.67)$ & $27(45.76)$ & $18(30)$ & $11(20.34)$ \\
molestus & $1(1.67)$ & $4(6.67)$ & $7(11.86)$ & $10(16.67)$ & $9(15.25)$ \\
hybrids & $19(31.67)$ & $31(51.67)$ & $24(40.68)$ & $32(53.33)$ & $37(62.71)$ \\
Total & 58 & 60 & 59 & 60 & 59 \\
\hline
\end{tabular}

These results thus confirm that the two forms coexist in the same breeding sites in Morocco. Note however that while the CQ11 PCR diagnostic test is sufficient to demonstrate hybridization at the population level, it provides only a crude approximation for the frequency of this hybridization, as it can be less accurate at the individual level. Further studies based on more discriminating tests (e.g. microsatellites,) are thus required for better estimations of the gene flow between the two forms.

3.3 Common target-site, but also metabolic resistance mutations, are present in Morocco, but their frequencies vary

We then measured the frequency of the most common resistance mutations, i.e. mutations at three locus encoding target proteins ( $v g s c$, ace-1 and $R d l$ ) and a gene encoding detoxifying esterases (Ester).

i) The A302S Rdl mutation allows resistance to dieldrin, an OC insecticide. For logistical reasons, it was tested only in Mohammedia, and found at a frequency of 0.19 , with similar frequencies between the molecular forms (LRT, $\chi^{2}=1.5, d f=4, p=0.83$ ). While dieldrin has 
been prohibited for a while, the persistence of $R d l$ resistance alleles is common in $C x$. pipiens populations and could be due to other pesticides, used against termites for example.

ii) The L1014F vgsc mutation ( $k d r)$, found worldwide in $C x$. pipiens (see review in ${ }^{22}$ ) and in other mosquitoes ${ }^{47}$, allows resistance to PYR insecticides. As suggested by previous studies, the L1014F mutation is present in Morocco 35,48. we found it in all populations tested, its frequency ranging from 0.08 in Mohammedia to 0.38 in Larache (Tab. 2). Two populations showed a significant departure from panmixia: a deficit of heterozygotes in Mohammedia, and excess in Agadir (Tab. 2).

Table 2: Resistance mutations frequencies in Morocco. For each population, the number $\mathrm{N}$ of mosquitoes analyzed is indicated (NB: the numbers can vary from one mutation to another, because some individuals could not amplify for all mutations tested, probably for technical reasons, e.g. conservation, resulting in poor quality for the extracted DNA), $f(R)$ indicates the frequency of the resistance allele, $F_{\text {is }}$ measures an excess $\left(F_{i s}<0\right)$ or a deficit $\left(F_{i s}>0\right)$ of heterozygotes compared to the panmixia expectation (Hardy-Weinberg equilibrium), and $P$ indicates the probability that these deviations are statistically significant (bold when significant).

\begin{tabular}{ccccccccccccccc}
\hline Samples & \multicolumn{4}{c}{ ace-1 G119S } & \multicolumn{4}{c}{ ace-1 F290V } & \multicolumn{4}{c}{ vgsc L1014F } \\
\hline & $\mathbf{N}$ & $\boldsymbol{f}(\boldsymbol{R})$ & $\boldsymbol{F}_{\text {is }}$ & $\boldsymbol{P}$ & $\mathbf{N}$ & $\boldsymbol{f ( R )}$ & $\boldsymbol{F}_{\text {is }}$ & $\boldsymbol{P}$ & & $\mathbf{N}$ & $\boldsymbol{f}(\boldsymbol{R})$ & $\boldsymbol{F}_{\text {is }}$ & $\boldsymbol{P}$ \\
\hline Tanger & $\mathbf{6 0}$ & 0.195 & -0.018 & 1 & $\mathbf{6 0}$ & 0.033 & -0.026 & 1 & & $\mathbf{5 7}$ & 0.34 & -0.2 & 0.15 \\
Larache & $\mathbf{5 9}$ & 0.242 & -0.311 & $\mathbf{0 . 0 1}$ & $\mathbf{6 0}$ & 0.192 & -0.229 & 0.10 & & $\mathbf{5 7}$ & 0.38 & -0.25 & 0.09 \\
Mohammedia & $\mathbf{6 0}$ & 0.083 & -0.083 & 1 & $\mathbf{5 8}$ & 0.112 & -0.118 & 1 & & $\mathbf{5 7}$ & 0.08 & 0.4043 & $\mathbf{0 . 0 3}$ \\
Marrakech & $\mathbf{6 1}$ & 0.172 & -0.2 & 0.19 & $\mathbf{5 9}$ & 0.051 & -0.045 & 1 & & $\mathbf{5 9}$ & 0.11 & 0.0576 & 0.52 \\
Agadir & $\mathbf{5 9}$ & 0.161 & -0.058 & 1 & $\mathbf{5 8}$ & 0.009 & - & - & & $\mathbf{5 9}$ & 0.31 & -0.432 & $\mathbf{5 . 1 0}-4$ \\
\hline
\end{tabular}

\begin{tabular}{|c|c|c|c|c|c|c|c|c|}
\hline \multirow[t]{2}{*}{ Samples } & \multicolumn{4}{|c|}{ RdI A302S } & \multicolumn{4}{|c|}{ Ester $^{2}$} \\
\hline & $\mathbf{N}$ & $f(R)$ & $F_{\text {is }}$ & $\boldsymbol{P}$ & $\mathbf{N}$ & $f(R)$ & $F_{\text {is }}$ & $P$ \\
\hline Tanger & & - & - & & 58 & 0.328 & -0.009 & 1 \\
\hline Larache & & - & - & & 54 & 0.583 & 0.3605 & 0.01 \\
\hline Mohammedia & 56 & 0.188 & 0.2466 & 0.08 & 59 & 0.737 & 0.3512 & 0.01 \\
\hline Marrakech & & - & - & & 59 & 0.636 & 0.2397 & 0.09 \\
\hline Agadir & & - & - & & 56 & 0.482 & -0.207 & 0.18 \\
\hline
\end{tabular}


No clear geographical pattern emerges, but there is significant geographic structuration at this locus (Fig. 3A). This is confirmed by statistical analyses using multinomial log-linear model (MLLM): we found no significant interaction of the Culex form and the locality on the genotypic frequencies distribution (LRT, $\chi^{2}=11.6, d f=20, p=0.93$ ), no effect of the form (LRT, $\chi^{2}=3, d f=6, p=0.80$ ), but the locality effect was significant (LRT, $\chi^{2}=78.5, d f=8$, $p=9.9 \times 10^{-14}$ ). PYR treatments thus appear pervasive in Morocco, although probably not homogenous in their intensity. Moreover, the high level of PYR resistance compared to the L1014F vgsc mutation frequencies (particularly in Mohammedia or Marrakesh, Figs. 2 and 3) suggests that other mechanisms, most probably overproduction of detoxifying enzymes from the cytochrome P450 oxidase family ${ }^{22}$, also contribute to this resistance in Morrocco (but they were not tested here).

iii) At the ace-1 locus, two mutations allow resistance to OP and CX insecticides. The F290V substitution is found only in Cx. pipiens, around the Mediterranean Sea, usually at low frequencies $26,34,49$. By contrast, the G119S substitution is found worldwide, close to fixation in some populations, and has been selected independently in many pest species ${ }^{25,39,50}$. While the G119S mutation had already been described in Morroco ${ }^{35,51}$, this is the first report for F290V in this country. We found both mutations in all regions, generally at relatively low frequencies, from $<0.01$ in Agadir to 0.19 in Larache for F290V, and from 0.08 in Mohammedia to 0.24 in Larache for G119S (Tab. 2). For both mutations, all populations displayed tendencies towards an excess of heterozygotes $\left(F_{I S}<0\right)$, although only one was significant, for G119S in Larache (Tab. 2). Such heterozygote excess has already been described in other populations of $C x$. pipiens, and may suggest the presence of duplicated alleles associating a susceptible and a resistant copy of ace-123,34,49,52,53. These alleles are quite frequent in $C x$. pipiens: they are selected because they display intermediate resistance and cost, which is adaptive in an environment with heterogeneous insecticide treatments ${ }^{54-56}$. However, further studies are required to confirm the presence and assess the identity of this or these alleles. 
While the F290V mutation appeared more frequent on the central coast, with strong geographic structuration (Fig. 3B), no clear geographical pattern emerges for G119S, with only very limited geographic structuration (Fig. 3C). MLLM revealed significant locality effect in both cases (LRT, F290V: $\chi^{2}=40.8, d f=8, p=2.2 \times 10^{-6}$; G119S: $\chi^{2}=19.7, d f=8$, $p=1.09 \times 10^{-2}$ ), but again no effect of the form (LRT, F290V: $\chi^{2}=4.7, d f=6, p=0.58$; G119S: $\left.\chi^{2}=0.99, d f=6, p=0.98\right)$ and no interaction (LRT, F290V: $\chi^{2}=15.6, d f=18, p=0.62$; G119S: $\left.\chi^{2}=12.3, d f=20, p=0.9\right)$.

iv) Several alleles of the Ester locus also allow resistance to OP insecticides: among them Ester $^{2}$ is found all over the World, ${ }^{21,57}$ and appears to be the only Ester allele found in Morocco. It was found in all populations at relatively high frequencies, from 0.33 in Tanger to 0.74 in Mohammedia. Two populations showed significant departures from panmixia, deficits in heterozygotes in Larache and Mohammedia that are probably due to Wahlund effects (Tab. 3). No clear geographical pattern emerges, but we found significant geographic structuration for this locus (Fig. 3D; MLLM, LRT; significant locality effect: $\chi^{2}=51.2, d f=8, p=2.4 \times 10^{-14}$; no form effect: $\chi^{2}=3,6, d f=6, p=0.73$; no interaction: $\left.\chi^{2}=24.4, d f=18, p=0.14\right)$. The high prevalence of OP resistance in Moroccan Culex populations probably reflects the continuous use since 1978 of temephos and chlorpyrifos to control mosquito larvae in this country ${ }^{35}$. It also explains why the ace-1 mutations (G119S and F290V) remain at lower frequencies than Ester $^{2}$, as the latter confers generally a higher resistance to OPs ${ }^{21,57}$. 
Table 3: Linkage disequilibrium. For each population (Pop), the p-value of the linkage disequilibrium between two loci (locus 1 and locus 2) is indicated; p-values $>$ à 0.05 are italicized, but none remained significant after multiple testing correction (Bonferoni). The overall disequilibrium (over all populations, Fisher method) is bolded. These statistics were computed using genepop.

\begin{tabular}{|c|c|c|c|}
\hline Pop & Locus1 & Locus2 & P-Value \\
\hline \multirow{10}{*}{ Mohammedia } & $k d r$ & ace-1(F290V) & 0.85 \\
\hline & $k d r$ & ace-1(G119S) & 1.00 \\
\hline & $k d r$ & $R d l$ & 0.91 \\
\hline & $k d r$ & Ester & 0.44 \\
\hline & ace-1(F290V) & ace-1(G119S) & 1.00 \\
\hline & ace-1(F290V) & $R d l$ & 1.00 \\
\hline & ace-1(F290V) & Ester & 0.08 \\
\hline & ace-1(G119S) & $R d l$ & 0.39 \\
\hline & асе-1(G119S) & Ester & 0.43 \\
\hline & $R d l$ & Ester & 0.30 \\
\hline \multirow{4}{*}{ Agadir } & $k d r$ & ace-1(F290V) & 1.00 \\
\hline & $k d r$ & ace-1(G119S) & 0.14 \\
\hline & $k d r$ & Ester & 0.59 \\
\hline & ace-1(F290V) & ace-1(G119S) & 1.00 \\
\hline
\end{tabular}




\begin{tabular}{|c|c|c|c|}
\hline & ace-1(F290V) & Ester & 0.18 \\
\hline & ace-1(G119S) & Ester & 0.38 \\
\hline \multirow{6}{*}{ Marrakech } & $k d r$ & ace-1(F290V) & 0.01 \\
\hline & $k d r$ & ace-1(G119S) & 0.20 \\
\hline & $k d r$ & Ester & 0.34 \\
\hline & ace-1(F290V) & ace-1(G119S) & 0.16 \\
\hline & ace-1(F290V) & Ester & 0.30 \\
\hline & ace-1(G119S) & Ester & 0.02 \\
\hline \multirow{6}{*}{ Tanger } & $k d r$ & ace-1(F290V) & 0.48 \\
\hline & $k d r$ & ace-1(G119S) & 0.03 \\
\hline & $k d r$ & Ester & 0.10 \\
\hline & ace-1(F290V) & ace-1(G119S) & 1.00 \\
\hline & ace-1(F290V) & Ester & 1.00 \\
\hline & ace-1(G119S) & Ester & 0.78 \\
\hline \multirow{6}{*}{ Larache } & $k d r$ & ace-1(F290V) & 0.35 \\
\hline & $k d r$ & асе-1(G119S) & 0.78 \\
\hline & $k d r$ & Ester & 0.07 \\
\hline & ace-1(F290V) & ace-1(G119S) & 1.00 \\
\hline & ace-1(F290V) & Ester & 0.72 \\
\hline & ace-1(G119S) & Ester & 0.09 \\
\hline \multirow{6}{*}{ All populations } & $k d r$ & ace-1(F290V)90V) & 0.26 \\
\hline & $k d r$ & ace-1(G119S)119S) & 0.15 \\
\hline & $k d r$ & Ester & 0.14 \\
\hline & ace-1(F290V)90V) & ace-1(G119S)119S) & 0.96 \\
\hline & ace-1(F290V)90V) & Ester & 0.33 \\
\hline & асе-1(G119S)119S) & Ester & 0.08 \\
\hline
\end{tabular}

\section{CONCLUSION}

Overall, we thus found that resistance is pervasive in Moroccan populations of $C x$. pipiens. We found no effect of the taxonomic form, which further suggests high gene flow between pipiens and molestus in Morocco, at least for the resistance alleles. While resistance levels and resistance allele frequencies against insecticides used for mosquito control in Morocco, OP and PYR, are high in all the populations, we also found that $C x$. pipiens populations are moderately resistant to more insecticide families. This suggests that they are exposed to many other pesticides than those used for mosquito control. The origin of these pesticides, whether 
from agriculture or urban residuals, should be investigated further to understand and measure their impact on resistance, which also requires a detailed knowledge of the histories of local treatments (a quite challenging endeavor). Our study is of course only a first assessment of the resistance distribution in Morocco, and more samples from many localities will be required to refine it, but general observations can already be made.

Resistance patterns are relatively similar between populations (Fig. 2), but we nevertheless found significant heterogeneity between the various localities. This suggests that the local selection intensity varies, and thus highlights the role of the local insecticide treatment practices or local pesticide exposure in the spread of resistance. Moreover, we did not find any linkage disequilibrium between the different mutations in any populations (Tab. 3): this suggests that the mosquitoes are also exposed to various selective pressures at the local scale. Part of this absence of linkage disequilibrium could also be due to the nature of the resistance mechanisms selected locally: similar PYR resistance levels are found in Larache and Mohammedia (Fig. 2), while L1014F frequencies are very different (Fig. 3), which strongly suggests the presence of other mechanisms (P450 oxidases).

More worryingly, the fact that OP and PYR resistances are already quite prevalent all over Morocco could impede mosquito control, while alternative insecticides are very limited. Beyond the nuisance and its impact on tourism, control failures could in this country lead to increased arbovirus transmission, as the WNV is actively circulating in Morocco ${ }^{58}$, which increases the risk of epizootics and epidemics. This risk is even further increased by the prevalence of resistance, as a study recently showed that resistance alleles tend to increase $C x$. pipiens competence for arboviruses ${ }^{31}$. This work must thus be furthered and refined to help the health authorities defined sustainable and effective vector control strategies.

\section{ACKNOWLEDGMENTS}

This study was funded by Institut Pasteur of Morocco and Institut des Sciences de l'Evolution de Montpellier. We thank Mr. Abbani Labaoui for his help in the mosquito collection.

\section{BIBLIOGRAPHY}

1 Organization WH and UNICEF, Global vector control response 2017-2030, World 
Health Organization (2017).

2 Weaver SC and Reisen WK, Present and future arboviral threats, Antiviral Res 85:328-345, Elsevier (2010).

3 Amraoui F, Krida G, Bouattour A, Rhim A, Daaboub J, Harrat Z, Boubidi SC, Tijane M, Sarih $M$ and Failloux AB, Culex pipiens, an experimental efficient vector of West Nile and Rift Valley fever viruses in the Maghreb region, PloS One 7:e36757 (2012).

4 Barrett AD, West Nile in Europe: an increasing public health problem, J Travel Med 25:tay096, Oxford University Press (2018).

5 Tber Abdelhaq A, West Nile fever in horses in Morocco, Bull Off Int Epizoot 108:867-869 (1996).

6 El Harrack M, Le Guenno B, and Gounon P, Isolement du virus West Nile au Maroc, Virologie 1:248-9 (1997).

7 Schuffenecker I, Peyrefitte CN, El Harrak M, Murri S, Leblond A, and Zeller HG, West Nile virus in Morocco, 2003, Emerg Infect Dis 11:306, Centers for Disease Control and Prevention (2005).

8 El Rhaffouli H, El Harrak M, Lotfi C, El Boukhrissi F, Bajjou T, Laraqui A, Hilali F, Kenfaoui $\mathrm{M}$ and Lahlou-Amine I, Serologic evidence of West Nile virus infection among humans, Morocco, Emerg Infect Dis 18:880, Centers for Disease Control and Prevention (2012).

9 Amraoui F, Tijane M, Sarih M, and Failloux A-B, Molecular evidence of Culex pipiens form molestus and hybrids pipiens/molestus in Morocco, North Africa, Parasit Vectors 5:83 (2012).

10 Spielman A, Population structure in the Culex pipiens complex of mosquitos, Bull World Health Organ 37:271, World Health Organization (1967).

11 Kassim NFA, Webb CE, and Russell RC, Culex molestus Forskal (Diptera: Culicidae) in Australia: colonisation, stenogamy, autogeny, oviposition and larval development, Aust J Entomol 51:67-77, Wiley Online Library (2012).

12 Pasteur N, Rioux JA, Guilvard E, and Pech-Perieres J, A new report of naturally anautogenous and stenogamic populations of Culex pipiens pipiens L. in the south of France (author's transl), Ann Parasitol Hum Comp 52:205-210 (1977).

13 Urbanelli S, Bullini L, and Villani F, Electrophoretic studies on Culex quinquefasciatus Say from Africa: genetic variability and divergence from Culex pipiens L.(Diptera: Culicidae), Bull Entomol Res 75:291-304 (1985).

14 Ishii T, On the Culex pipiens group in Japan Part III. A historical review of its research 4. Review of the adult character (3)., J Sci Univ Tokushima 13:29-62 (1980).

15 Farajollahi A, Fonseca DM, Kramer LD, and Kilpatrick AM, "Bird biting” mosquitoes and human disease: a review of the role of Culex pipiens complex mosquitoes in epidemiology, Infect Genet Evol 11:1577-1585, Elsevier (2011).

16 Faraj C, Adlaoui E, Elkohli M, Herrak T, Ameur B, and Chandre F, Review of Temephos Discriminating Concentration for Monitoring the Susceptibility of Anopheles labranchiae (Falleroni, 1926), Malaria Vector in Morocco, Malar Res Treat, 2010. https://www.hindawi.com/journals/mrt/2010/126085/ [accessed 12 February 2020].

17 Haubruge É and Amichot $\mathrm{M}$, Les mécanismes responsables de la résistance aux insecticides chez les insectes et les acariens, BASE (1998). 
18 Hemingway J, Hawkes NJ, McCarroll L, and Ranson H, The molecular basis of insecticide resistance in mosquitoes, Insect Biochem Mol Biol 34:653-665 (2004).

19 Labbé P, Alout H, Djogbénou L, Pasteur N, and Weill M, Evolution of resistance to insecticide in disease vectors, Genetics and evolution of infectious disease, Elsevier, pp. 363409 (2011).

20 Nkya TE, Akhouayri I, Kisinza W, and David J-P, Impact of environment on mosquito response to pyrethroid insecticides: facts, evidences and prospects, Insect Biochem Mol Biol 43:407-416, Elsevier (2013).

21 Labbé $\mathrm{P}$, Lenormand $\mathrm{T}$, and Raymond $\mathrm{M}$, On the worldwide spread of an insecticide resistance gene: a role for local selection, J Evol Biol 18:1471-1484 (2005).

22 Scott JG, Yoshimizu MH, and Kasai S, Pyrethroid resistance in Culex pipiens mosquitoes, Pestic Biochem Physiol 120:68-76, Elsevier (2015).

23 Milesi P, Assogba BS, Atyame CM, Pocquet N, Berthomieu A, Unal S, Makoundou P, Weill $\mathrm{M}$ and Labbé $\mathrm{P}$, The evolutionary fate of heterogeneous gene duplications: a precarious overdominant equilibrium between environment, sublethality and complementation, Mol Ecol 27:493-507, Wiley Online Library (2018).

$24 \mathrm{Xu} \mathrm{Q}$, Liu $\mathrm{H}$, Zhang L, and Liu N, Resistance in the mosquito, Culex quinquefasciatus, and possible mechanisms for resistance, Pest Manag Sci Former Pestic Sci 61:1096-1102, Wiley Online Library (2005).

25 Weill M, Lutfalla G, Mogensen K, Chandre F, Berthomieu A, Berticat C, Pasteur N, Philips A, Comparative genomics: Insecticide resistance in mosquito vectors, Nature 423:136 (2003).

26 Alout H, Berthomieu A, Hadjivassilis A, and Weill M, A new amino-acid substitution in acetylcholinesterase 1 confers insecticide resistance to Culex pipiens mosquitoes from Cyprus, Insect Biochem Mol Biol 37:41-47 (2007).

27 Tantely ML, Tortosa P, Alout H, Berticat C, Berthomieu A, Rutee A, Dehecq JS, Makoundou P, Labbé P, Pasteur N and Weill M, Insecticide resistance in Culex pipiens quinquefasciatus and Aedes albopictus mosquitoes from La Reunion Island, Insect Biochem Mol Biol 40:317-324 (2010).

28 Golenda C and Forgash AJ, Fenvalerate cross-resistance in a resmethrin-selected strain of the house fly (Diptera: Muscidae), J Econ Entomol 78:19-24, Oxford University Press Oxford, UK (1985).

29 Scott JG, Cross-resistance to the biological insecticide abamectin in pyrethroidresistant house flies, Pestic Biochem Physiol 34:27-31, Elsevier (1989).

30 Bisset J, Rodriguez M, Soca A, Pasteur N, and Raymond M, Cross-resistance to pyrethroid and organophosphorus insecticides in the southern house mosquito (Diptera: Culicidae) from Cuba, J Med Entomol 34:244-246, Oxford University Press Oxford, UK (1997).

31 Atyame CM, Alout H, Mousson L, Vazeille M, Diallo M, Weill M, and Failloux AB, Insecticide resistance genes affect Culex quinquefasciatus vector competence for West Nile virus, Proc R Soc B 286:20182273, The Royal Society (2019).

32 WHO, Global report on insecticide resistance in malaria vectors: 2010-2016, World Health Organization Geneva (2018).

33 Benjelloun A, El Harrak M, Calistri P, Loutfi C, Kabbaj H, Conte A, Ippoliti C, 
Danzetta ML and Belkadi B, Seroprevalence of West Nile virus in horses in different Moroccan regions, Vet Med Sci 3:198-207, Wiley Online Library (2017).

34 Alout H, Labbé P, Pasteur N, and Weill M, High incidence of ace-1 duplicated haplotypes in resistant Culex pipiens mosquitoes from Algeria, Insect Biochem Mol Biol 41:29-35, Elsevier (2011).

35 Tmimi F-Z, Faraj C, Bkhache M, Mounaji K, Failloux A-B, and Sarih M, Insecticide resistance and target site mutations (G119S ace-1 and L1014F kdr) of Culex pipiens in Morocco, Parasit Vectors 11:51 (2018).

36 Georghiou GP, Metcalf RL, and Gidden FE, Carbamate-resistance in mosquitos: Selection of Culex pipiens fatigans Wiedemann (= C. quinquefasciatus Say) for resistance to Baygon, Bull World Health Organ 35:691 (1966).

37 Bahnck CM and Fonseca DM, Rapid assay to identify the two genetic forms of Culex (Culex) pipiens L.(Diptera: Culicidae) and hybrid populations, Am J Trop Med Hyg 75:251255 (2006).

38 Martinez-Torres D, Chevillon C, Brun-Barale A, Bergé JB, Pasteur N, and Pauron D, Voltage-dependent $\mathrm{Na}+$ channels in pyrethroid-resistant Culex pipiens L mosquitoes, Pestic Sci 55:1012-1020 (1999).

39 Weill M, Malcolm C, Chandre F, Mogensen K, Berthomieu A, Marquine M, nd Raymond $\mathrm{M}$, The unique mutation in ace-1 giving high insecticide resistance is easily detectable in mosquito vectors, Insect Mol Biol 13:1-7 (2004).

40 Berticat C, Dubois M-P, Marquine M, Chevillon C, and Raymond M, A molecular test to identify resistance alleles at the amplified esterase locus in the mosquito Culex pipiens, Pest Manag Sci Former Pestic Sci 56:727-731, Wiley Online Library (2000).

41 Raymond M, GENEPOP (version 1.2): population genetics software for exact tests and ecumenicism, $J$ Hered 86:248-249 (1995).

42 Weir BS and Cockerham CC, Estimating F-statistics for the analysis of population structure, evolution 38:1358-1370 (1984).

43 Milesi P, Lenormand T, Lagneau C, Weill M, and Labbé P, Relating fitness to longterm environmental variations in natura, Mol Ecol 25:5483-5499, Wiley Online Library (2016).

44 Mouhamadou CS, de Souza SS, Fodjo BK, Zoh MG, Bli NK, and Koudou BG, Evidence of insecticide resistance selection in wild Anopheles coluzzii mosquitoes due to agricultural pesticide use, Infect Dis Poverty 8:64, Springer (2019).

45 Tabbabi A, Daaboub J, Laamari A, Ben-Cheikh R, Feriani M, Boubaker C, Ben-Jha I and Ben-cheikh $\mathrm{H}$, Impacts of agricultural practices on pyrethroid resistance in Culex pipiens pipiens, an important vector of human diseases, from Tunisia, Trop Biomed 36:542-549, Malaysian Society of Parasitology and Tropical Medicine (2019).

46 Brown FV, Logan RAE, and Wilding CS, Carbamate resistance in a UK population of the halophilic mosquito Ochlerotatus detritus implicates selection by agricultural usage of insecticide, Int J Pest Manag 65:284-292, Taylor \& Francis (2019).

47 Coleman M, Hemingway J, Gleave KA, Wiebe A, Gething PW, and Moyes CL, Developing global maps of insecticide resistance risk to improve vector control, Malar $J$ 16:86, Springer (2017).

48 Bkhache M, Tmimi F-Z, Charafeddine O, Faraj C, Failloux A-B, and Sarih M, First 
report of L1014F-kdr mutation in Culex pipiens complex from Morocco, Parasit Vectors 9:644 (2016).

49 Alout H, Labbé P, Berthomieu A, Pasteur N, and Weill M, Multiple duplications of the rare ace-1 mutation F290V in Culex pipiens natural populations, Insect Biochem Mol Biol 39:884-891, Elsevier (2009).

50 Alout H, Berthomieu A, Cui F, Tan Y, Berticat C, Qiao C, et al., Different amino-acid substitutions confer insecticide resistance through acetylcholinesterase 1 insensitivity in Culex vishnui and Culex tritaeniorhynchus (Diptera: Culicidae) from China, $J$ Med Entomol 44:463-469, Oxford University Press Oxford, UK (2007).

51 Bkhache M, Tmimi F-Z, Charafeddine O, Filali OB, Lemrani M, Labbé P and Sarih M, G119S ace-1 mutation conferring insecticide resistance detected in the Culex pipiens complex in Morocco, Pest Manag Sci 75:286-291 (2019).

52 Labbé P, Berthomieu A, Berticat C, Alout H, Raymond M, Lenormand T and Weill $\mathrm{M}$, Independent duplications of the acetylcholinesterase gene conferring insecticide resistance in the mosquito Culex pipiens, Mol Biol Evol 24:1056-1067, Oxford University Press (2007). 53 Osta MA, Rizk ZJ, Labbé P, Weill M, and Knio K, Insecticide resistance to organophosphates in Culex pipiens complex from Lebanon, Parasit Vectors 5:132, Springer (2012).

54 Labbé P, Milesi P, Yébakima A, Pasteur N, Weill M, and Lenormand T, Gene-dosage effects on fitness in recent adaptive duplications: ace-1 in the mosquito Culex pipiens, Evolution 68:2092-2101, Wiley Online Library (2014).

55 Assogba BS, Djogbénou LS, Milesi P, Berthomieu A, Perez J, Ayala D, Chandre F, Makoutodé $\mathrm{M}$, Labbé $\mathrm{P}$ and Weill $\mathrm{M}$, An ace-1 gene duplication resorbs the fitness cost associated with resistance in Anopheles gambiae, the main malaria mosquito, Sci Rep 5:1-12, Nature Publishing Group (2015).

56 Milesi P, Weill M, Lenormand T, and Labbé P, Heterogeneous gene duplications can be adaptive because they permanently associate overdominant alleles, Evol Lett 1:169-180, Wiley Online Library (2017).

57 Raymond M, Berticat C, Weill M, Pasteur N, and Chevillon C, Insecticide resistance in the mosquito Culex pipiens: what have we learned about adaptation?, Microevolution Rate, Pattern, Process, Springer, pp. 287-296 (2001).

58 Assaid N, Mousson L, Moutailler S, Arich S, Akarid K, Monier M, Beck C, Lecolinet $\mathrm{S}$, Failloux $\mathrm{AB}$ and Sarih M, Evidence of circulation of West Nile virus in Culex pipiens mosquitoes and horses in Morocco, Acta Trop 205:105414, Elsevier (2020). 


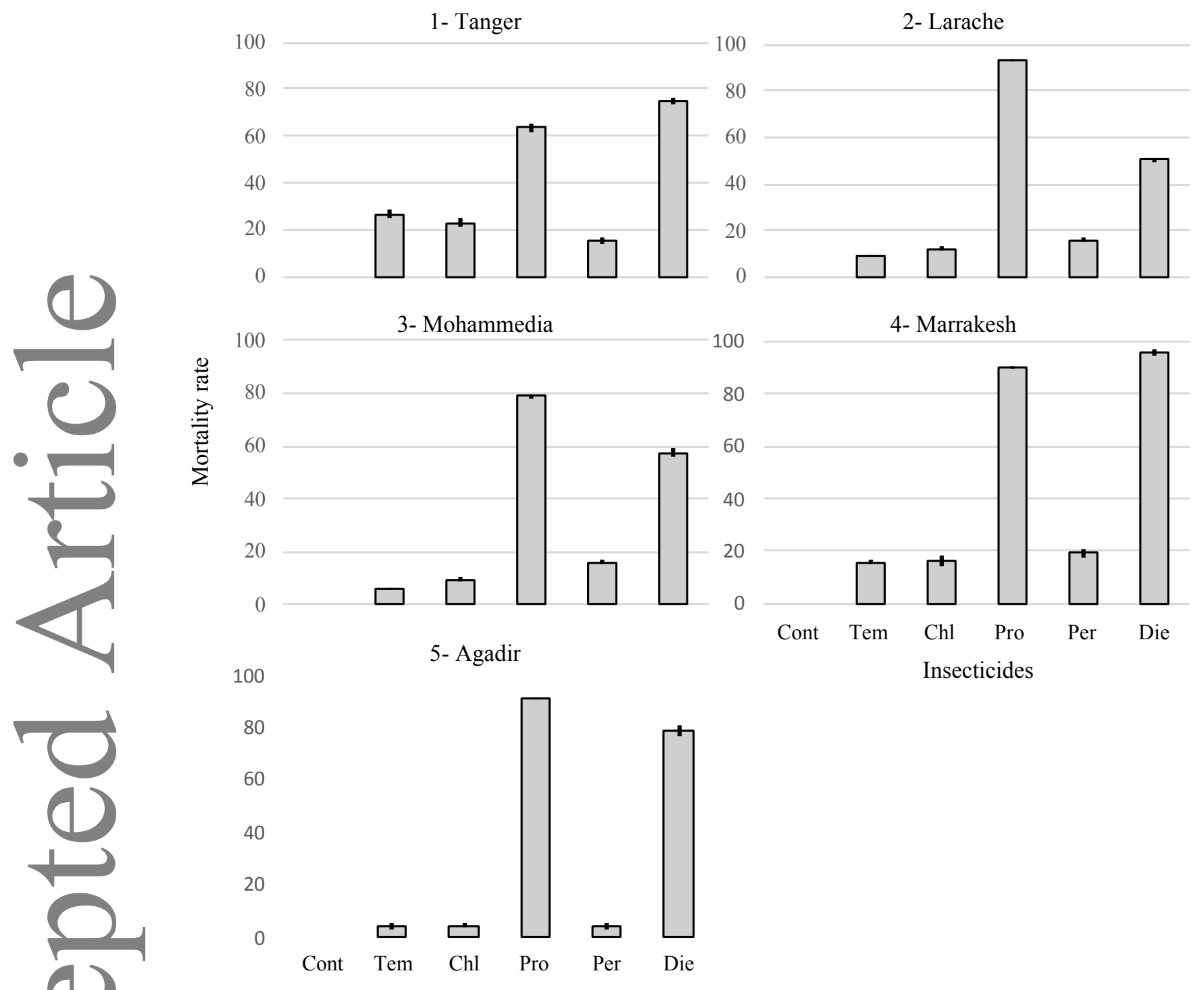

Figure 2 : Larval mortality after exposure in the different sampled localities. For each locality, the mortality rate after $24 \mathrm{~h}$ exposure of fourth instar larvae in single-diagnostic-dose bioassay (see methods), to various insecticides, temephos (Tem, $0.0003 \mathrm{mg} .1-1$ ), chorpyrifos (Chl, 0.003 mg.l-1), propoxur (Pro, 2 mg.l-1), permethrin (Per, 0.005 mg.l-1) and dieldrin (Die, 0.01 g.1-1), or in the unexposed controls (Cont). 

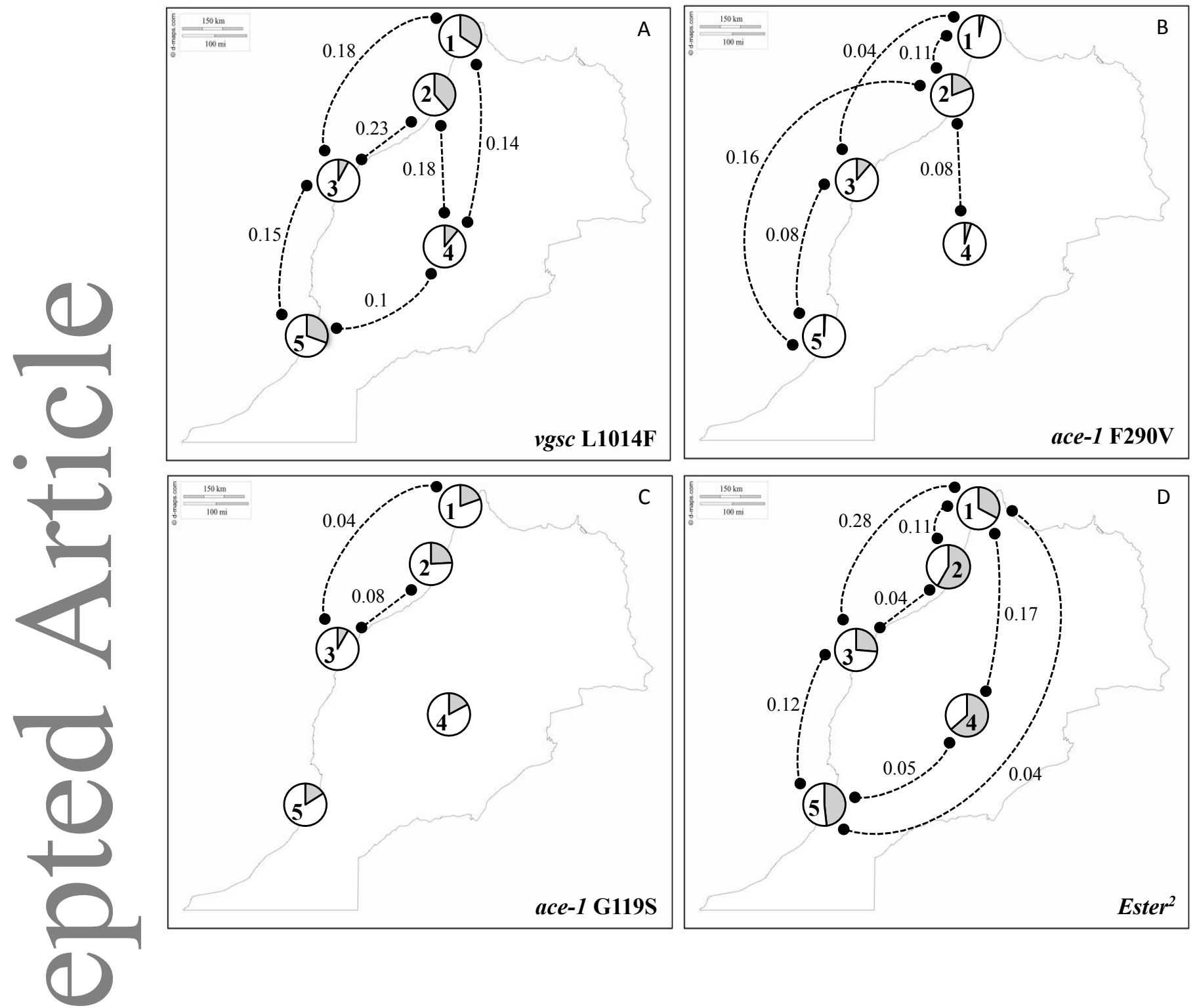

Figure 3: Distribution of the resistance mutations frequencies in Morocco. For each locus and each mutation (A, B, C and D), and for each population sampled (numbers as in Fig. 1), the frequencies of the resistant allele are represented by the grey sectors in each circle. The genetic differentiation between two populations, i.e. the $F_{s t}$ value, is indicated by the links: all pairs of populations have been tested, but only pairs with statistically significant genic differentiation (exact G-test, genepop, $p<0.05$ ) are indicated. NB: the $R d l$ mutation is not represented as only one population was analyzed. 